\title{
Keindahan Terselubung Web Series Sore : Kajian Estetika
}

\author{
Destyanisa Tazkiyah \\ Fakultas Ilmu Budaya, Universitas Jenderal Soedirman \\ tazkiya112@gmail.com
}

\begin{abstract}
This article discusses the aesthetic assessment of the web series Sore which is done through a semiotic approach, as well as the beauty of delivering the moral message behind the purpose of the web series as advertisement. The first step on the research is to develop basic narrative scheme to guide the determination of the main signifiers in the web series. Next is to analyze the style of language contained in the dialogue that has a metaphor in it. And finally, the aesthetic assessment of the delivery of moral messages in the web series. After analyzing the authors found the hidden beauty of the web series Sore is the simple form of main signifier, the use of metaphors that have beauty as supporting the delivery of the meaning in some scenes on the web series, as well as the web series successfully deliver the moral messages with such a natural and beautiful scene that accordance with the purpose of literature to entertain and educate.
\end{abstract}

Keywords : Aesthetics; semiotics; language style; web series.

\section{Intisari}

Artikel ini membahas mengenai penilaian estetika web series Sore yang dilakukan melalui pendekatan semiotika, serta keindahan penyampaian pesan moral dibalik tujuan web series sebagai iklan. Langkah pertama yang dilakukan adalah menyusun skema naratif dasar untuk menuntun penentuan signifier (penanda) utama dalam web series. Selanjutnya adalah menganalisis gaya bahasa yang terdapat dalam dialog yang memiliki metafor di dalamnya. Dan terakhir adalah penilaian estetika dari penyampaian pesan moral dalam web series. Setelah melakukan analisis penulis menemukan keindahan terselubung web series Sore berupa, signifier utama yang sederhana, penggunaan metafor yang memiliki keindahan sebagai pendukung penyampaian makna adegan dalam web series, serta suksesnya penyampaian pesan moral secara alami dan indah sesuai dengan tujuan karya sastra yang menghibur dan mendidik.

Kata kunci : Estetika; semiotika; gaya bahasa; web series.

\section{Pendahuluan}

Di zaman milenial ini genre sastra semakin mengalami perkembangan. Salah satu yang sedang digandrungi oleh para muda-mudi di Negara kita adalah web series. Web series adalah cerita bersambung audio visual yang diunggah di situs internet Youtube. Web series termasuk dalam kategori sastra cyber. Sastra cyber merupakan suatu revolusi, cybersastra ini merupakan aktivitas sastra yang memanfaatkan komputer dan internet (Endraswara, 2013). Internet menawarkan kebebasan tanpa sensor dengan memanfaatkan teknologi seperti mailing list (milis), situs, forum diskusi, dan blog. Semua orang boleh memajang karyanya dan semua boleh mengapresiasinya (Wijayanti, 2017). 
Sama halnya dengan drama dan film, web series merupakan karya yang terdiri atas aspek sastra dan aspek pementasan. Aspek sastra web series berupa skrip atau skenario yang kemudian dialih wahanakan menjadi bentuk audio visual yaitu web series yang kita tonton. Penulis memilih web series Sore sebagai objek material yang akan dianalisis. Web series garapan sutradara Yandy Laurens yang bekerja sama dengan brand Tropicana Slim ini berjumlah 9 episode, dengan durasi masing-masing episodenya sekitar 8 sampai 15 menit. Setiap episodenya di upload melalui situs Youtube. Yandy Laurens adalah seorang filmmaker muda yang sedang naik daun, salah satu filmnya yang terbaru adalah Keluarga Cemara yang rilis pada tahun 2018 .

Web series ini menarik untuk diteliti, selain berupa cerita bersambung dengan durasi pendek dimana merupakan bentuk sastra cyber yang sedang populer, tujuan awal web series yaitu sebagai iklan namun disampaikan dengan kaidah sastra yang estetik menjadi nilai tambahan. Peneliti menemukan beberapa rujukan dari beberapa penelitian terdahulu di antaranya (1) Penelitian Pujiatusti (2018) yang berjudul "Makna Hidup Sehat, Mengejar Cinta, dan Masa Depan; Interpretasi Simbol Pada Web Series Sore - Istri Dari Masa Depan Karya Yandy Laurens ". Penelitian dengan kajian semiotika ini difokuskan pada simbol-simbol yang terdapat dalam web series dan interpretasi atau pemaknaan dari setiap simbol. Hasil analisis yaitu ditemukan tujuh simbol yang mencerminkan cerita web series Sore yaitu cinta, istri, suami, romantic pengorbanan, kebebasan, dan kesetiaan.

Penelitian terkait dilakukan oleh (2) Anzani (2018) dengan menganalisis web series Sore sebagai media baru kampanye digital untuk hidup sehat. Pendekatan yang digunakan adalah pendekatan kualitatif dengan paradigma Post Positivisme. Hasil penelitian menemukan bahwa penggunaan web series Sore merupakan metode perusahaan Tropicana Slim guna mencapai target pasaran yaitu generasi muda usia produktif dan menghilangkan citra Tropicana Slim sebagai produk orang tua. Penggunaan situs Youtube sebagai media penempatan iklan komunikasi sesuai dengan karakteristik media baru. Pesan kampanye hidup sehat yang terdapat dalam web series disampaikan tanpa menggurui, struktur pesan dibuat secara implisit sehingga mendapar respon positif dari generasi muda pengguna Youtube.

Dalam melakukan penilaian estetika penulis akan menganalisis web series berdasarkan 3 aspek. Pertama, dengan pendekatan semiotika menentukan penanda (signifier) utama yang mewakili semua indeks, simbol, dan ikon dalam web series melalui skema naratif dasar. Kedua, gaya bahasa pada dialog antar tokoh. Ketiga, nilai moral yang terkandung dibalik web series Sore. 


\section{Metode Penelitian}

Metode penelitian yang digunakan adalah metode deskriptif kualitaif. Pengumpulan data dilakukan dengan teknik kepustakaan dengan mengumpulkan data pustaka atau rujukan dari berbagai sumber. Perspektif kajian dalam penelitian ini adalah estetika, dengan pendekatan semiotika. Objek material penelitian adalah web series Sore yang berjumlah 9 episode. Hasil penelitian diperoleh melalui tiga tahapan analisis : (1) mengidentifikasi skema naratif dasar yang terdapat dalam web series yang dilakukan dengan cara mengobservasi dialog antar tokoh serta menganalisis ikon, simbol dan indeks yang terdapat dalam adegan web series, (2) mencermati dialog antar tokoh dan mengidentifikasi gaya bahasa yang memiliki metafor di dalamnya, (3) melakukan penilaian estetika dari penyampaian pesan moral dalam web series.

\section{Hasil dan Pembahasan}

Keindahan dalam Tanda

Menurut Charles Sanders Peirce tanda terdiri dari ikon (tanda yang muncul dari perwakilan fisik), simbol (tanda yang tidak serupa dengan yang ditandainya), dan indeks (tanda yang muncul dari hubungan sebab-akibat) (Kaelan, 2009). Langkah pertama yang dilakukan adalah menentukan skema naratif dasar, dengan menyusun plot cerita dari awal sampai akhir. Setelahnya adalah menemukan tanda atau sign yang terdapat dalam web series yang akan menuntun penulis dalam menentukan signifier utama yaitu tanda yang mewakili semua tanda-tanda yang ada. Berikut adalah skema naratif dasar web series Sore :

1) Sore kembali ke masa lalu dimana Jo masih bekerja di Italia,

2) Sore memaksa Jo untuk mengubah gaya hidupnya,

3) Jo tak menyangka dirinya mati muda di masa depan,

4) Jo kembali ke tanah air,

5) Jo bertemu dengan Sore di masa sekarang.

Skema naratif dasar web series Sore diawali dengan munculnya Sore dikehidupan Jonathan atau yang biasa disapa Jo secara tiba-tiba dan mengaku sebagai istrinya dari masa depan. Kehadiran Sore yang sangat tiba-tiba dan tidak masuk akal tentu saja membuat Jo terheran-heran, awalnya jo menolak keras kehadiran Sore namun lambat laun Jo mulai menerima Sore. Kedatangan Sore bukan tanpa tujuan, ia memiliki sebuah misi. 
Sore berusaha mengubah gaya hidup Jo yang buruk, ia membuang minuman keras dan rokok milik Jo, setiap hari selalu memaksa Jo untuk lari pagi, untuk tidak begadang hingga larut malam, dan selalu makan makanan sehat. Jo tentu awalnya enggan melakukan semua itu, Sore dan Jo bertengkar hebat hingga tanpa sadar Sore mengatakan bahwa Jo mati muda di masa depan. Jo sangat terkejut mendengar pernyataan Sore, sejak itu Jo perlahan mengubah gaya hidupnya. Sekembalinya Jo ke tanah air, Jo mencari Sore. Sore di masa sekarang ini tentu tidak mengenal Jo. Jo berusaha mendapatkan hati Sore dan menjalin hubungan dengannya.

Melalui tahap observasi penulis mengelompokan berbagai petanda yang terdapat dalam web series sesuai dengan jenisnya, yaitu :

1) Tanda : minuman keras, rokok, makanan kolesterol tinggi, salad,

2) Simbol : begadang, olah raga, lari pagi, diabetes.

3) Indeks : perjalanan waktu, mati muda.

Setelah menemukan skema naratif dasar dan petanda dari keseluruhan web series, selanjutnya adalah menentukan signifier utama dari web series Sore. Signifier ini bisa berupa ikon, simbol, atau indeks yang bisa dikaitkan dengan unsur lain dalam keseluruhan web series. Ketiga jenis tanda ini sebenarnya tidak perlu terpisah antara satu dengan yang lain, sesuatu bisa merupakan ikon, simbol dan indeks, atau kombinasi ketiganya. Film, misalnya, menggunakan ketiga kategori ini sekaligus : ikon berupa bunyi dan gambar, simbol yaitu ujaran dan tulisan, serta indeks yaitu hasil yang difilmkan (Wardoyo, 2005).

Indeks "Jo mati muda di masa depan" merupakan signifier utama dalam web series Sore. "Jo mati muda di masa depan" adalah kejadian yang membuat Sore melakukan perjalanan waktu ke masa lalu, dimana Jo selalu menerapkan gaya hidup yang buruk yang akhirnya membuatnya mengidap diabetes tipe II dan menjadi penyebab kematiannya di masa depan. Sore berusaha mencegah hal itu terjadi dengan pergi ke masa lalu dan merubah gaya hidup Jo. "Jo mati muda di masa depan" merupakan signifier utama yang dominan, signifier ini merupakan inti yang membangun keseluruhan cerita.

\section{Keindahan Gaya Bahasa}

Dalam web series Sore terdapat beberapa dialog antar tokoh yang cukup puitis. Dalam dialogdialog ini tentu mengandung gaya bahasa. Berikut adalah salah satu kutipan dialog fenomenal 
yang akan saya bahas, dialog ini disampaikan oleh tokoh Sore kepada Jo di masa lalu, yang ternyata di masa depan diucapkan oleh Jo untuk merayu Sore :

"Kamu tau nggak kenapa senja selalu menyenangkan? Kadang dia hitam kelam, kadang dia merah merekah. Tapi langit selalu menerima senja apa adanya."

Dalam kutipan di atas terdapat metafora di dalamnya. Metafora adalah gaya bahasa perbandingan yang singkat, padat dan tersusun rapi. Di dalamnya terlihat dua gagasan, yang satu adalah suatu kenyataan, sesuatu yang dipikirkan dan yang menjadi objek, dan yang satunya lagi merupakan pembanding terhadap kenyataan tadi dan menggantikan yang di belakang itu menjadi yang terdahulu. Metafora merupakan bahasa kiasan seperti perbandingan hanya saja tidak menggunakan kata pembanding seperti, ibarat, bagaikan, umpama, laksana, dll.

Melalui metafora akhirnya dihasilkan makna konotatif, selain itu timbulah keindahan darinya. Dari sudut pandang semiotika, kita bisa melakukan penafsiran konotatif, yang pertama yaitu dengan menemukan sebuah metafor dan melihat dengan alasan apa vehicle mewakili tenor. Vehicle adalah aspek kiasan sebuah ekspresi, yang digabung dengan konteksnya yang direkonstruksi. Tenor adalah aspek literal sebuah ekspresi dengan konteks literalnya yang direkonstruksi. Selanjutnya adalah menentukan arti konotatif dari sebuah kata atau frase yang ada dalam metafor tersebut.

Kutipan diatas adalah kalimat gombalan atau rayuan, tujuan kalimat rayuan adalah meluluhkan hati siapa saja yang mendengarnya. Agar tujuan ini tercapai tentu saja kalimat rayuan harus memiliki unsur-unsur keindahan yang dapat menyentuh hati sang lawan bicara. Jika kita bongkar kalimat rayuan ini, maka transposisi metaforik berdasarkan vehicle dan tenornya dapat diilustrasikan seperti di bawah ini :

$\begin{array}{lccccc}\text { Vehicle : Kadang dia } & \text { hitam kelam } \quad \text {, kadang dia merah merekah } \\ & \downarrow & \downarrow & & \downarrow & \downarrow \\ \text { Tenor : } & \text { Sore } & \text { sifat buruk, } & & \text { Sore } & \text { sifat baik }\end{array}$

Dia adalah kata ganti untuk orang, namun disini digunakan sebagai kata ganti "senja". Senja adalah kiasan yang merepresentasikan tokoh Sore. Selanjutnya, hitam kelam; warna hitam bisanya identik dengan kesedihan atau sesuatu yang buruk, kelam adalah kata pelengkap hitam sebagai penjelas. Saya cenderung menafsirkan hitam kelam adalah representasi dari "sifat buruk", 
atau bisa diartikan sebagai sisi kelam dari Sore. Warna merah identik dengan sesuatu yang menyenangkan dan bahagia, merekah adalah kata pelengkap sebagai penjelas. Dalam kalimat ini hitam kelam dan merah merekah adalah sesuatu yang berlawanan, sehingga saya cenderung menafsirkan merah merekah adalah representasi dari "sifat baik", atau sisi kebaikan yang dimiliki Sore. Kalimat selanjutnya jika dijelaskan melalui bagan adalah sebagai berikut :

$\begin{array}{lccc}\text { Vehicle: Tapi langit selalu menerima senja apa adanya } \\ & \downarrow & & \downarrow \\ \text { Tenor : } & \text { Jo } & \text { Sore } & \end{array}$

Seperti yang telah dijelaskan di atas, senja adalah representasi dari Sore. Pada kalimat ini terdapat kata langit yang merupakan kiasan yang merepresentasikan tokoh Jo. Jika kita melihat kenyataan berdasar fenomena alam waktu senja tiba, matahari yang mulai tenggelam akan memancarkan warna merah merekah di langit, yang kemudian secara perlahan akan berubah menjadi hitam kelam seiring dengan datangnya malam. Bagaimana pun juga senja akan selalu datang setiap hari, dan langit akan selalu ada menyertainya. Kejadian alam ini dijadikan perbandingan yang digunakan dalam metafora. Makna konotatif dari keseluruhan kalimat adalah Sore memiliki sifat buruk yang terkadang akan muncul dan bisa jadi menyebalkan, terkadang juga sifat baiknya akan menyenangkan, namun bagaimana pun juga Jo tetap menerima Sore apa adanya dan tak memaksanya untuk berubah.

Jika mendengar kalimat ini untuk pertama kali keindahan yang kita rasakan tentunya adalah dari pemilihan kata dan frase yang digunakan, sederhana dan tak berbelit-belit. Setelah menggali makna yang terdapat di dalamnya tentu kita menemukan keindahan yang terselubung di dalamnya. Bagaimana senja dan langit digunakan sebagai kiasan yang merepresentasikan kedua tokoh, serta didukung dengan adegan dalam web series yang berlatar di atas tebing dekat pantai saat matahari tenggelam, semua hal ini semakin menambah keindahan momen romantis itu.

Keindahan Penyampaian Pesan Moral Melalui Alur Cerita

Web series Sore menceritakan seorang istri yaitu Sore yang melakukan perjalanan waktu ke masa lalu untuk menemui laki-laki yang menjadi suaminya di masa depan. Sore tentunya pergi ke masa lalu bukan tanpa tujuan, ia mengemban sebuah misi. Kemunculan Sore yang sangat 
tiba-tiba dan mengaku sebagai istri dari masa depan tentu saja membuat Jonathan sangat terkejut dan merasa aneh. Sejak hadirnya Sore, Jo dipaksa untuk mengubah gaya hidupnya. Sore selalu memaksa Jo untuk lari pagi, Sore juga membuang semua rokok dan minuman beralkohol milik Jo, ketika makan Sore selalu memastikan Jo makan banyak sayuran dan menghindari junkfood, selain itu Sore juga selalu membatasi agar Jo tidak terlalu banyak minum kopi, teh, dan minuman bersoda.

Web series ini ditayangkan oleh situs Youtube brand Tropicana Slim, tujuan utama web series ini sebenarnya adalah iklan. Namun dari episode pertama hingga terakhir tidak ada satu kalipun kemunculan produk-produk dari Tropicana Slim. Alur cerita mengalir dengan sangat natural, penonton dibawa pergi ke dalam dunia imajinasi, layaknya menaiki roller coaster perasaan dimana perasaan kita dibawa naik turun oleh jalan cerita. Awal cerita yang dibuka dengan premis menarik yaitu datangnya Sore yang mengaku sebagai istri dari masa depan, kesan pertama saya sebagai penonton adalah penasaran. Setelahnya tentu menjadi bahagia karena banyak terdapat kejadian-kejadian kikuk namun lucu antara Jo dan Sore, mereka mulai dekat dan Jo mulai memiliki rasa yang lebih kepada Sore.

Roller coaster perasaan ini tiba-tiba membawa penonton terjun bebas ketika konflik cerita terjadi, Sore dan Jo bertengkar hingga akhirnya Sore tanpa sengaja mengatakan bahwa Jo telah meninggal di masa depan. Dari sini penonton pun mulai dapat menerka-nerka cerita. Sekali lagi keindahan terselubung mulai terasa, sang sutradara tidak pernah menjelaskan secara rinci mengenai tujuan Sore melakukan perjalanan waktu kembali ke masa lalu, dengan alur yang mengalir natural penonton dengan imajinasinya mampu menafsirkan kemana cerita berjalan. Sore kembali ke masa lalu, memakasa Jo untuk menerapkan gaya hidup sehat tidak lain adalah demi memiliki umur yang lebih panjang, menjadi sehat dan bisa mencegah kematiannya.

Tropicana Slim adalah merek produk dagang asli Indonesia yang menyediakan produkproduk untuk mengontrol dan mencegah diabetes. Diabetes dapat disebabkan oleh gaya hidup yang buruk, seperti mengkonsumsi makanan dan minuman tinggi gula, tidak pernah berolah raga, serta pola tidur yang tidak baik. Gaya hidup buruk ini semuanya dimiliki oleh tokoh Jo. Kehadiran tokoh Sore dari masa depan memiliki sebuah misi untuk merubah gaya hidup Jo menjadi gaya hidup yang lebih sehat agar kelak di masa depan Jo tidak mengidap diabetes yang menyebabkannya meninggal dunia.

Sang sutradara berhasil menyampaikan pesan moral tentang gaya hidup sehat dengan menggunakan alur cerita yang ia buat. Web series Sore tidak hanya mengangkat kisah cinta yang 
romantis saja, tetapi juga mengandung pesan moral untuk mewujudkan rasa sayang terhadap orang terkasih dan keluarga dengan mengajak mereka menjalankan pola hidup sehat bersamasama. Suatu karya dikatakan memiliki nilai estetis jika mampu menimbulkan pengalaman estetis bagi penikmatnya (Ratna, 2015). Sebagai karya sastra web series ini berhasil menyampaikan pesan moral tersebut dengan indahnya, sesuai dengan fungsi karya sastra yang menghibur sekaligus mendidik.

\section{Simpulan}

Setelah melakukan analisis, penulis menemukan fakta bagaimana pendekatan semiotika dapat membantu proses penilaian estetika suatu karya sastra. Setelah menyusun skema naratif dasar, dapat ditentukan signifier atau penanda utama web series Sore adalah "Jo mati muda di masa depan", ini adalah kejadian yang membuat Sore melakukan perjalanan waktu ke masa lalu dan berupaya merubah gaya hidup Jo menjadi lebih baik. Ini adalah penanda utama yang dominan, signifier ini merupakan inti yang membangun keseluruhan cerita.

Selanjutnya adalah makna konotatif dari metafor yang terdapat dalam dialog rayuan "Kadang dia hitam kelam, kadang dia merah merekah. Tapi langit selalu menerima senja apa adanya" yang memiliki keindahan terselubung. Makna keseluruhanya adalah Sore memiliki sifat buruk yang terkadang akan muncul dan bisa jadi menyebalkan, terkadang juga sifat baiknya akan menyenangkan, namun bagaimana pun juga Jo tetap menerima Sore apa adanya. Langit digunakan sebagai metafor yang merepresentasikan Jo, dan senja adalah Sore.

Keindahan terselubung yang paling mendalam adalah pesan moral yang tersampaikan secara alami melalui alur cerita. Meski tujuan utama web series adalah sebagai iklan produk Tropicana Slim, sang sutradara mampu menyampaikan pesan moral tentang gaya hidup sehat demi mencegah diabetes dengan indahnya melalui kisah cinta yang romantis antara tokoh Jo dan Sore. Dari episode awal hingga akhir tidak ada kemunculan produk Tropicana Slim sehingga membuat penonton mampu menikmati web series dan bisa mengambil pesan moral yang terkandung di dalamnya tanpa terbebani dengan asumsi web series ini sebagai produk iklan.

\section{Daftar Pustaka}

Anzani, Wilda Aulia. 2018. Web Series Sore Sebagai Media Baru Kampanya Digital Hidup Sehat. Skripsi. Universitas Sultan Ageng Tirtayasa.

Endraswara, Suwardi. 2013. Metodologi Penelitian Sastra,Epistemologi, Model, Teori dan Aplikasi. Yogyakarta: CAPS (Center for Academic Publishing Service).

Fiske, John. 1990. Introduction to Communication Studies. London : Routledge. 
Kaelan. 2009. Filsafat Bahasa Semiotika dan Hermeneutika. Yogyakarta : Paradigma Indonesia Monaco, James. 1981. How to Read a Film. New York : Oxford Unversity Press.

Pujiastuti, Tri. 2018. Makna Hidup Sehat, Mengejar Cinta, dan Masa Depan; Interpretasi Simbol Pada Web Series Sore-Isri dari Masa Depan Karya Yandy Laurens. Skripsi. Universitas Diponegoro.

Ratna, Nyoman Kutha. 2015. Estetika Sastra dan Budaya. Yogyakarta : Pustaka Pelajar.

Teeuw, A. 1983. Membaca dan Menilai Sastra. Jakarta: Gramedia

Wardoyo, Subur. 2005. Semiotika dan Struktur Narasi. Kajian Sastra, vol.29, No.1, Januari 2005

Wijayanti,Rika.http://rika-wijayanti.blogspot.com/2017/02/cybersastra-generasipostliterasi.html publish Minggu, 19 febuari 2017. Diakses pada 12 Agustus 2019 